\title{
Clinical Evaluation of a Patient With Symptoms of Colonic or Anorectal Motility Disorders
}

\author{
Bryan Curtin, Enoe Jimenez, and Satish S C Rao* \\ Division of Gastroenterology and Hepatology, Digestive Health Center, Augusta University, Medical College of Georgia, Augusta, GA, USA
}

Constipation, irritable bowel syndrome, fecal incontinence, abdominal pain, and anorectal pain are problems that affect $40 \%$ of the population. They commonly present with overlapping symptoms indicating that their pathophysiology affects multiple segments of the gut as well as brain and gut interactions. Clinically, although some conditions are readily recognized, dyssynergic defecation, fecal incontinence, and anorectal pain are often missed or misdiagnosed. Consequently, the assessment of lower gastrointestinal symptoms in patients with suspected colonic or anorectal motility disorder(s) remains challenging for most clinicians. A detailed history, use of the Bristol stool form scale, prospective stool diaries, ideally through a phone App, digital rectal examination, and judicious use of complementary diagnostic tests are essential. Additionally, it is important to evaluate the impact of these problems on quality of life and psychosocial issues, because they are intricately linked with these disorders. The Rome IV diagnostic questionnaire for functional gastrointestinal disorders can provide additional information often missed during history taking. Here, we discuss a systematic approach for the clinical evaluation of patients with suspected lower gastrointestinal problems, grouped under 4 common diagnostic categories. We describe how to take a detailed history, perform meticulous digital rectal examination, and use validated tools to supplement clinical evaluation, including assessments of quality of life and scoring systems for disease severity and digital Apps. These tools could facilitate a comprehensive plan for clinical management including diagnostic tests, and translate the patients' complaints into definable, diagnostic categories.

(J Neurogastroenterol Motil 2020;26:423-436)

Key Words

Anorectal pain; Constipation; Diagnostic tests, routine; Fecal incontinence; Irritable bowel syndrome

\section{Introduction}

Lower gastrointestinal (GI) symptoms that suggest a motility or functional GI disorder can affect $40 \%$ of the population. ${ }^{1}$ These patients present to gastroenterologists and primary care physicians ${ }^{2,3}$ with a variety of common overlapping symptoms. Teasing out the precise problem(s) requires a careful appraisal of symptoms, a meticulous physical examination, particularly digital rectal examination, and the use of validated tools that can better explain the effects of their symptoms on quality of life (QOL) and psychosocial issues., ${ }^{2,3}$ However, there is a dearth of knowledge on how to evaluate these patients, often resulting in multiple, often wasteful and invasive procedures. Through a systematic, evidence-based approach, it should be possible to assign these patients under different diagnostic categories. However, a precise diagnosis usually requires objective tools such as anorectal manometry, balloon expulsion test, imaging, defecography, neurophysiology tests, etc. Here, we provide an over-

Received: January 23, 2020 Revised: August 11, 2020 Accepted: August 16, 2020

() This is an Open Access article distributed under the terms of the Creative Commons Attribution Non-Commercial License (http://creativecommons. org/licenses/by-nc/4.0) which permits unrestricted non-commercial use, distribution, and reproduction in any medium, provided the original work is properly cited.

*Correspondence: Satish S C Rao, MD, PhD, FRCP (LON)

Division of Gastroenterology and Hepatology, Digestive Health Center, Augusta University, Medical College of Georgia, 1120 15th

Street, AD 2226, Augusta, GA 30912, USA

Tel: +1-706-721-2238, Fax: +1-706-723-0382, E-mail: srao@augusta.edu 
view of our approach to patients with suspected colonic or anorectal disorders.

In order to navigate the complex array of overlapping symptoms described by patients with suspected lower GI disorder, we have grouped them under the following clinical categories: constipation, irritable bowel syndrome (IBS), fecal incontinence (FI), and anorectal pain disorders. First, we describe the common symptoms and diagnostic criteria for each of the aforementioned conditions. Table 1 provides a list of common lower GI complaints and the likelihood of their prevalence in each of the conditions, based on the available literature, ${ }^{1-11}$ and our experience in the field. Second, we discuss the various scoring systems for the assessment of disease severity, as well as additional tools for their evaluation such as prospective stool diaries, digital Apps, and QOL measures, and examine the challenges with these assessments. Third, we emphasize the role of physical and digital rectal examination, and how their findings can aid clinical diagnosis. Finally, we describe the role of current and novel diagnostic tests that could facilitate an optimal diagnosis of these disorders. We trust that this approach will provide an improved understanding of these common and overlapping symptoms and their impact, as well as provide an up-to-date overview of clinical tools that are currently available to characterize these conditions and monitor their progress.

\section{Constipation}

Constipation is one of the most common complaints in both primary care and gastroenterology offices. ${ }^{1-4}$ It is associated with an ever-increasing burden on the healthcare system which includes inpatient admissions, particularly in the elderly. ${ }^{5,6}$ However, it remains a very challenging condition to characterize because constipation can occur from a wide variety of etiologies, which can include metabolic disorders, use of constipating drugs that slow the bowel, IBS, or defecatory disorders. ${ }^{7}$ Although rare, it is important to assess for more serious conditions such as intestinal obstruction or neurologic disease such as Parkinson's disease or connective tissue disorders such as Ehlers-Danlos Syndrome. ${ }^{7}$ Here, we have supplemented the recent guidelines from the American Gastroenterological Association and American Society for Gastrointestinal Endoscopy ${ }^{8,9}$ with our own experience to improve clinical diagnosis and management.

The term "constipation" is nonspecific and refers to a constellation of symptoms reported by a patient to describe that there is a disturbance in their bowel function. ${ }^{7,8}$ However, it is very important for the clinician to identify what exactly the patient means when they complain of constipation. ${ }^{3,7,8,10}$ Some patients use the term to describe the firmness of their stools. Others will refer specifically to the size of their stools, sensing a problem if their stools are too small (Table 1). Another common description of constipation focuses on stool frequency, and historically constipation has been defined this way for both clinical research and practice. ${ }^{10}$ However, defining constipation purely by stool frequency is an inherently flawed practice, as while it may detect patients with IBS or slow transit constipation, it is very poor at detecting constipation due to defecatory disorders. ${ }^{2,3,7,8}$ An older survey reported that up to $60 \%$ of young patients that described themselves as "constipated" had bowel movements on a daily basis, which underscores how incomplete this

Table 1. Symptom Profiles That Are Usually Reported by Patients Within Each Diagnostic Category (As Can Be Seen There Is Significant Overlap of Symptoms Between Patients From Each Category)

\begin{tabular}{|c|c|c|c|c|c|}
\hline Symptom & $\begin{array}{l}\text { Slow transit } \\
\text { constipation }\end{array}$ & $\begin{array}{l}\text { Dyssynergic } \\
\text { defecation }\end{array}$ & IBS-C & $\begin{array}{c}\text { Fecal } \\
\text { incontinence }\end{array}$ & $\begin{array}{c}\text { Anorectal pain } \\
\text { syndrome }\end{array}$ \\
\hline Straining & + & ++ & + & $+/-$ & $+/-$ \\
\hline Hard stools & ++ & ++ & + & - & $+/-$ \\
\hline Incomplete evacuation & $+/-$ & ++ & $+/-$ & + & - \\
\hline Infrequent bowel movement & ++ & \pm & + & $+/-$ & $+/-$ \\
\hline Anal blockage & $+/-$ & ++ & $+/-$ & $+/-$ & $+/-$ \\
\hline Abdominal pain & $+/-$ & $+/-$ & ++ & - & $+/-$ \\
\hline Anal pain & - & $+/-$ & - & - & ++ \\
\hline Diarrhea & - & - & - & + & - \\
\hline Stool leakage & - & $+/-$ & - & ++ & - \\
\hline Anal pruritus & - & - & - & $+/-$ & $+/-$ \\
\hline Digital maneuvers & $+/-$ & ++ & $+/-$ & $+/-$ & $+/-$ \\
\hline
\end{tabular}

IBS-C, irritable bowel syndrome with predominant constipation; ++ , strong feature of the condition; + , usually reported and present; $+/-$, may or may not be present; -, usually absent. 
descriptor is for constipation. ${ }^{11}$

The challenge of how to define constipation was addressed by the Rome IV international working committee which proposed criteria for diagnosis of constipation and is contingent upon the onset of symptoms 6 months prior to diagnosis and a prevalence for at least 3 months. ${ }^{2}$

(1) Must include 2 or more of the following:

\section{a. Straining}

b. Lumpy or hard stools (Bristol stool form scale [BSFS] 1-2)

c. Sensation of incomplete evacuation

d. Sensation of anorectal obstruction/blockage

e. Manual maneuvers to facilitate

f. Fewer than 3 spontaneous bowel movements per week

(2) Loose stools are rarely present without the use of laxatives

(3) Insufficient criteria for IBS

Alarm signs, such as sudden change in bowel habits after the age of 50, hematochezia, new onset iron deficiency, unexplained weight loss, or presence of a family history of colon cancer should always warrant aggressive investigation, usually with a colonoscopy or in certain cases, cross sectional imaging, but in their absence constipation should be suspected. ${ }^{2}$

In the evaluation of constipation, the temporal relationship between the onset of symptoms and potential risk factors should be identified. ${ }^{7,8,10,11}$ Did the symptoms start when the patient began a new medication, or has it been going on since childhood? A history of abuse has been shown to correlate with the onset of constipation in school age children. ${ }^{12,13}$ While difficult to ask, inquiring about a history of abuse or sexual trauma in a confidential manner can be very informative with regards to the etiology of a patient's constipation or other defecatory dysfunction. ${ }^{2,12}$ Getting more information about the "call to stool," such as whether it is post-prandial, or initiated by abdominal discomfort or rectal sensation is also recom- mended, as this may give information on whether the patient has a coexisting rectal sensory problem contributing to their anorectal disorder. ${ }^{7,13}$ Does the patient use digital maneuvers to begin or continue the process of defecation? Visual images of stool form, specifically the BSFS (Fig. 1) and bowel diaries can be more reliable methods to characterize the bowel habits as well as the patient-reported stool frequency and risk factors. ${ }^{14} \mathrm{~A}$ recent mobile phone app, that culls information about key constipation symptoms that a patient can keep prospectively for 1-2 weeks could significantly change the approach of accurately documenting bowel symptoms and enable improved treatment (Fig. 2). ${ }^{15}$ Additional symptoms such as abdominal bloating, distention, or discomfort and non-GI symptoms

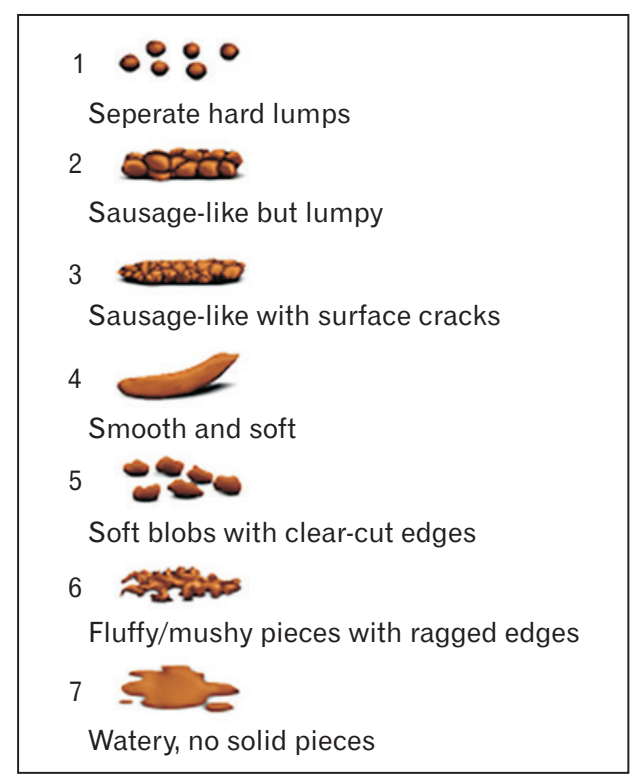

Figure 1. Bristol Stool form scale for describing patients stool form and accurately characterizing bowel movements.

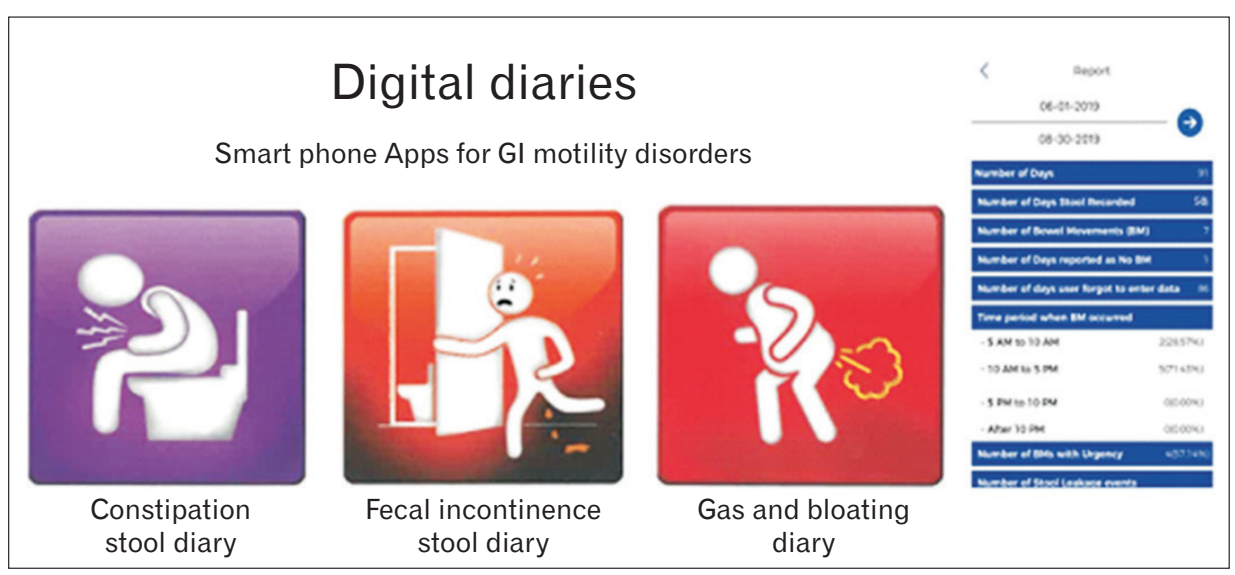

Vol. 26, No. 4 October, 2020 (423-436)
Figure 2. Digital diaries for recording symptoms in patients with suspected chronic constipation, fecal incontinence, and gas and bloating, and a sample of the report generated by the App. GI, gastrointestinal. 
such as fatigue, malaise, or psychosocial distress are worth assessing. Constipation will frequently present with abdominal bloating as a patient's most bothersome complaint. ${ }^{15,16}$ Using BSFS and stool diaries, combined with the patient's description of symptoms is an effective way to assess if the diagnostic criteria of IBS has been met. ${ }^{2}$

Many patients have significant overlap of constipation symptoms with others such as abdominal pain, bloating, distention, and nausea. ${ }^{2,7,10,17}$ Patients are often unclear about the temporal relationship between abdominal discomfort and bowel habits. In general, patients who report abdominal pain report poorer overall health and a greater decline in QOL secondary to their GI symptoms. ${ }^{17}$ The term "functional or idiopathic constipation" is rarely used by clinicians because a significant proportion of these patients will have identifiable pathophysiologic abnormalities such as slow colonic transit, dyssynergic defecation, IBS with predominant constipation (IBS-C), opioid-induced constipation, or other secondary causes. ${ }^{3,4,7}$

\section{Irritable Bowel Syndrome}

IBS is characterized by the presence of chronic abdominal pain associated with an altered bowel habit. ${ }^{2}$ Sensations of abdominal discomfort, bloating, distention, and difficult defecation are associated. ${ }^{7,11,14,17}$ with IBS, and often there is a significant overlap (Table 1). IBS accounts for $15-20 \%$ of all referrals to gastroenterologists in the United States of America (USA), and is a significant source of financial burden. ${ }^{2,18}$ Historically, IBS has been considered a diagnosis of exclusion, as it can mimic common organic diseases, and these should be ruled out before diagnosing IBS. However, there is increasing evidence including expert consensus that clinically, physicians should take a positive approach and use the Rome diagnostic criteria, and minimize the use of laboratory and endoscopic studies. ${ }^{2}$

While there is a significant inter-subject variability, several characteristic traits are generally seen across all cases of IBS. ${ }^{19}$ There is a low risk of increased mortality, or development of malignancy or inflammatory bowel disease. There is a significant overlap of IBS with other symptomatic GI disorders such as gastroesophageal reflux disease, dyspepsia, and normal-transit constipation. ${ }^{20} \mathrm{No}_{0}$ universal pathophysiologic mechanism has been demonstrated in IBS, but visceral hypersensitivity is generally accepted as a key underlying mechanism. ${ }^{2,21}$ IBS symptoms also tend to follow some commonly observed patterns; symptoms may be episodic and are often associated with food intake and/or defecation., ${ }^{2,17,20}$ These symptoms may be of sufficient severity to interfere with their daily life and social functioning. ${ }^{2}$ Many patients may have developed IBS as a consequence of a previous intestinal infection ${ }^{22}$ or major life event/stressor, such as an abdominal/pelvic trauma or surgery. ${ }^{2,13,20,21}$ Antibiotic use may also precipitate symptoms. ${ }^{22}$

The Rome IV criteria defines IBS as recurrent abdominal pain, on average, at least 1 day per week in the last 3 months, and associated with 2 of the following 3 criteria: (1) related to defecation, (2) associated with a change in frequency of the stool, and (3) associated with a change in form (appearance) of the stool. ${ }^{2}$ The major changes from Rome III include removal of the term "discomfort" and an increase in the frequency requirement from 3 days/month to a least 1 day per week. ${ }^{2}$ IBS encompasses at least 4 main types that are summarized below ${ }^{2,23}$ :

(1) IBS with predominant constipation (IBS-C): $>25 \%$ of bowel movement with BSFS types 1 or 2 and $<25 \%$ of bowel movements with BSFS types 6 or 7

(2) IBS with predominant diarrhea (IBS-D): $>25 \%$ of bowel movements with BSFS types 6 or 7 and $<25 \%$ of bowel movements with BSFS types 1 or 2

(3) IBS with mixed bowel habits (IBS-M): $>25 \%$ of bowel movements with BSFS types 6 or 7 and $>25 \%$ of bowel movements with BSFS types 1 or 2

(4) IBS Unclassified (IBS-U): Patients who meet diagnostic criteria for IBS but whose bowel habits cannot be accurately categorized into one of the 3 groups above.

It should be noted that all subtypes described above can only be confidently established when the patient is evaluated off all medications used to treat bowel habit abnormalities. ${ }^{2,23}$ Patients also commonly transition between these subtypes, so re-assessment of subtype should occur on a regular basis. ${ }^{2,18,19}$ Further subtyping of IBS patients may be helpful based on the presence of additional symptoms. These subtypes may include, IBS with predominant bowel dysfunction, IBS with predominant pain, IBS with predominant bloating or IBS associated with precipitating factors such as post-infectious IBS, food-induced IBS, and stress-related IBS. $^{18,22}$ The aforementioned subtyping is helpful to the clinician as it guides both pharmacological and behavioral therapy. Because of the overlapping nature of symptoms, and sometimes teasing out the individual components can be challenging or if patients are not able to articulate their symptoms clearly, a problem not uncommon in this population, the use of detailed questionnaires such as the Rome IV diagnostic questionnaire for functional GI disorders can provide useful supplemental information. ${ }^{24}$ Given the high prevalence of IBS in the general population, and the fact that it is commonly diagnosed in the community after excluding organic disorders, often a costly endeavor, ${ }^{1,2,19}$ we implore that more research is conducted into cost-effective approaches for diagnosis of IBS such as using 
better designed symptom questionnaires and/or biomarkers.

\section{Fecal Incontinence}

Fecal incontinence (FI) is the involuntary loss of liquid or solid stool from the rectum. ${ }^{25}$ The burden of FI is thought to be grossly underestimated by most clinicians. ${ }^{3,25,26}$ Recent community-based USA data suggested that FI affects 20 million adults in the USA, nearly $10 \%$ of the population. ${ }^{22,27}$ This underestimation is likely due to multiple barriers, but the most common is the reluctance of physicians to specifically address and ask about FI combined with patient's embarrassment in reporting it. ${ }^{25,26}$ Therefore, in addition to assessing symptoms suggestive of constipation and IBS, it is absolutely essential to enquire about the possible presence of FI.

Continence is maintained through a complex, fine-tuned system of factors that include stool volume/consistency, rectal compliance, anal sphincter function, sensation, and reflex, neurologic innervation, and cognitive ability. ${ }^{25,28}$ Because several barriers help to preserve fecal continence, stool incontinence usually occurs when one or more mechanisms are defective. ${ }^{28,29}$ Clinically, FI is subcategorized into 3 different types, which has clinical and prognostic significance and is summarized below. ${ }^{25,28}$

(1) Passive incontinence: loss of stool without the urge to defecate, mainly attributable to internal anal sphincter dysfunction and peripheral neuropathy

(2) Urge incontinence: inability to postpone defecation urge, related mainly to external anal sphincter dysfunction

(3) Fecal seepage: involuntary loss of small amounts of stool, incomplete evacuation which may be related to impaired rectal sensation

In the case of FI, it is essential to fully characterize the history of the incontinence to distinguish it from other symptoms more commonly associated with diarrhea, such as frequency and urgency without loss of bowel contents. ${ }^{30}$ Often patients may not describe this symptom out of sheer embarrassment or the associated social stigma and instead describe diarrhea or urgency (Table 1$).^{25}$ Other important factors to consider include an assessment of the amount of stool and its character (staining vs full movement that is lost), duration, frequency, and presence of nocturnal episodes. ${ }^{25} \mathrm{~A}$ prospective 7-14 day stool diary is very useful to both understand symptoms and improve accuracy of diagnosis rather than relying on patient's recall that can be problematic. ${ }^{31} \mathrm{~A}$ recent comparative study suggested that a digital diary APP-FI stool diary is as accurate as a paper form stool diary (Fig. 2). ) $^{32,33}$

Because FI is frequently associated with neurological condi- tions, special attention should be paid to the presence of lower back pain, perineal sensations, urinary incontinence, and symptoms affecting the lower extremities as this could point to an underlying neurologic cause of $\mathrm{FI}^{25}$ An extensive surgical history, including obstetrical history, should be obtained..$^{25}$ The presence of prolapse of rectal contents can also be helpful in this evaluation. ${ }^{25,26,34}$

There have been several risk factors identified for FI, which include obstetric trauma, anal trauma, surgery, pelvic radiotherapy, smoking, obesity, diabetes, and pre-existing neurologic conditions. ${ }^{25-27}$ There is a greater prevalence of $\mathrm{FI}$ amongst females when compared to males, which is generally attributed to maternal injuries sustained during childbirth, although some studies have shown similar prevalence across gender. ${ }^{3,26-28}$ However, there are other factors that may play a role in FI, particularly in the elderly such as menopause, age-related changes to the pelvic floor, and pudendal neuropathy. ${ }^{3,26,28}$

\section{Anorectal Pain Disorders}

Once organic causes are excluded there are 3 main types of functional anorectal pain disorders: levator ani syndrome (LAS), proctalgia fugax, and unspecified. ${ }^{3,35,36}$ LAS is characterized by an ill-defined, aching or pressure sensation in the rectum that is often exacerbated by sitting (Table 1). ${ }^{3}$ The exact cause of LAS is not known but it is hypothesized to cause symptoms because of spasm of the pelvic floor combined with elevated resting pressures. ${ }^{3,35,36}$ However, there is likely overlap with dyssynergic defecation and other anorectal disorders. ${ }^{36}$ More recent data suggests that lumbar and sacral neuropathy may be an important pathophysiological mechanism in LAS. ${ }^{37,38}$ Data on characterization of LAS is limited, but diagnostic criteria have been proposed. ${ }^{3}$

Must include all of the following:

(1) Chronic or recurrent rectal pain or aching

(2) Episodes last 30 minutes or longer

(3) Tenderness during traction on the puborectalis

(4) Exclusion of other causes of rectal pain

It has been estimated that LAS is the cause of approximately $5-10 \%$ of anorectal pain, and thus should always be considered as a possible diagnosis for patients presenting for evaluation for related complaints. ${ }^{3}$ The other major described entity of anorectal pain is proctalgia fugax. In contrast to LAS, proctalgia fugax presents as a sudden severe pain in the rectum that typically lasts seconds to minutes before disappearing just as rapidly. ${ }^{3,39}$ These attacks rarely last longer than 30 minutes in duration and can be quite infrequent, occurring less than 5 times per year in more than half of patients. ${ }^{40}$ 
The pain has been described as "shock-like" and ranges from uncomfortable to unbearable. Many patients have to stop their daily activities to deal with the onset of symptoms, and sometimes they may even be awakened from sleep. ${ }^{41}$ The diagnostic criteria for proctalgia fugax is as follows ${ }^{3}$ :

Must include all of the following:

(1) Recurrent episodes of pain localized to the rectum and unrelated to defecation

(2) Episodes last from seconds to minutes, with a maximum duration of 30 minutes

(3) There is no anorectal pain between episodes

(4) Exclusion of other causes of rectal pain

\section{Scoring Systems for the Assessment of Patient With Lower Gastrointestinal Symptoms Suggesting Motility Disorders -}

One significant challenge in assigning a diagnosis for patients with lower GI symptoms is the lack of specificity of patient-reported symptoms and identifying their severity. When it comes to stool habit, particularly stool frequency, consistency, straining effort or use of digital maneuvers, reliance on patient's memory and recall of bowel habits is unreliable. ${ }^{42,43}$ Objective scoring systems and prospective stool diaries for common lower GI symptoms have been developed and utilized to aid in this assessment. ${ }^{44,45}$ Recently, digital Apps (Fig. 2) that accurately capture symptoms and provide a comprehensive prospective report of bowel habits in both FI and constipation have been developed. ${ }^{15,32,33,46}$ BSFS is a verified tool for characterizing stool caliber. ${ }^{47}$ The "Constipation Scoring System" has also been developed ${ }^{45}$ that features 100 constipation-related symptoms on a questionnaire and then compared with physiologic testing. Eight symptoms, including frequency of bowel movements, painful evacuation, incomplete evacuation, abdominal pain, length of time per attempt, assistance for evacuation, unsuccessful attempts for evacuation per 24 hours, and duration of constipation were found to correlate with physiologic testing. This scoring system has been used for over 25 years, but mostly for clinical research. ${ }^{45,48}$ Another assessment tool is the Patient Assessment of Constipation Symptoms (PAC-SYM), which is a reproducible and internally consistent assessment that contains 12 items assigned to 3 subscales: stool symptoms, rectal symptoms, and abdominal symptoms. ${ }^{49} \mathrm{~A}$ more complete assessment can be made using a stool diary and assessing the number of complete spontaneous bowel movements (CSBMs) throughout a typical week. ${ }^{44,46}$ A CSBM is defined as a bowel movement without use of laxative or enema within previous
24 hours and with a sense of complete satisfactory evacuation. ${ }^{50}$ When assessing the response to treatment for constipation in a clinical trial, a "responder" is generally defined as a patient with $>3$ CSBMs per week and an increase of at least 1 CSBM from their baseline. ${ }^{50}$ The advantage of using CSBMs is that it takes into account the spontaneity and caliber of bowel movement as well as the degree of satisfaction with evacuation rather than simply relying on bowel frequency, which can be misleading. Finally, the Patient Assessment of Constipation Quality of Life (PAC-QOL) is also a useful tool for measuring the health-related QOL for patients afflicted with constipation. ${ }^{51}$ This assessment tool is based on the Wilson and Cleary model of health outcomes linking biological and physiological factors with patient-based symptoms, general health perceptions, and overall QOL. ${ }^{52}$ It is composed of 28 items grouped into 4 subscales related to dissatisfaction, physical discomfort, psychosocial discomfort, worries and concerns. ${ }^{51}$ The scores range from 0-4 with lower scores indicating better QOL, and in general a 1-point improvement is considered as a significant response to treatment. ${ }^{51}$ As previously mentioned, smartphone Apps to help with patient's self-logging of constipation symptoms is already in use (Fig. 2). For IBS, several scoring systems including abdominal pain numerical rating systems, IBS severity scoring system, IBS-QOL, NIH GI PROMIS, and others have been validated and considered useful. Their strengths and weaknesses have been summarized in a recent article. $^{53}$

With regards to FI, several additional scoring systems have been developed. The Cleveland Clinic Florida FI score has been widely used (Fig. 3). ${ }^{54}$ St Mark's Incontinence score is a somewhat updated version of the Cleveland clinic score that more clearly specifies the frequency and adds additional elements such as the need to wear a pad or use constipating medicines. ${ }^{55}$ The Fecal Incontinence Severity Index (FISI) is based on a frequency matrix, including all 4 types of leakage commonly found in the fecal incontinent population: gas, mucous, liquid stool, and solid stool combined with

\begin{tabular}{lccccc} 
& \multicolumn{5}{c}{ Frequency } \\
\cline { 2 - 6 } $\begin{array}{l}\text { Type of } \\
\text { incontinence }\end{array}$ & Never & Rarely & Sometimes & Usually & Always \\
Solid & 0 & 1 & 2 & 3 & 4 \\
Liquid & 0 & 1 & 2 & 3 & 4 \\
Gas & 0 & 1 & 2 & 3 & 4 \\
Wears pad & 0 & 1 & 2 & 3 & 4 \\
Lifestyle & 0 & 1 & 2 & 3 & 4 \\
$\quad$ alteration & & & &
\end{tabular}

Figure 3. Fecal incontinence severity evaluation scale for clinicians. Adapted from Jorge and Wexner. ${ }^{54}$ 
frequency data. It has been validated and compared favorably with regards to patient and surgeon reported evaluations of severity, and even correlates with QOL measures. ${ }^{56}$ With regards to QOL, the Rockwood Fecal Incontinence Quality of Life (FIQOL) scale is a verified scale that assesses 29 items that involve lifestyle, coping/ behavior, depression/self-perception, and embarrassment. ${ }^{57}$ Psychometric evaluation of this scale revealed that it was reliable, reproducible, and demonstrated internal reliability. ${ }^{57}$ All of these FI symptom scoring systems are acceptable models to more objectively record patient's symptoms/quality of life and gauge treatment responses in both a research and clinical setting. Clearly, patient reported outcome instruments are key for improving clinical care and research. A recent report has validated the use of $50 \%$ reduction in FI episodes, as a useful patient reported outcome measure for assessing improvement in $\mathrm{FI}^{58,59}$

\section{Challenges With Objective Assessment and Scoring Systems}

Despite the myriad scoring systems and QOL tools, significant limitations exist, as common lower GI symptoms generally tend to have low predictive value of the ultimate diagnosis. ${ }^{60,61}$ As previously mentioned, primary constipation is typically classified as either slow transit, IBS-related, or related to outlet dysfunction. ${ }^{3,47}$ However, a large proportion of patients will have an evacuation disorder, such as dyssynergic defecation which is defined by paradoxical anal or puborectalis contraction or inadequate propulsive forces of the rectum and pelvic floor muscles during defecation. ${ }^{3,4,7}$ These symptoms are typically associated with straining, feeling of incomplete evacuation, or digital maneuvers, but these symptoms cannot reliably distinguish patients with dyssynergia from patients with slow transit constipation, which necessitates the use of motility-based testing to establish this diagnosis. ${ }^{60-62}$

Similar challenges confront the diagnosis of FI. Leakage of stool, while having a sensitivity of nearly $100 \%$ for the detection of manometrically detected low resting sphincter pressure, had a low specificity of $11 \%$ and a positive predictive value of $51 \% .^{63}$ The positive predictive value of detecting a low squeeze pressure was better, at $80 \%{ }^{63}$ Even the use of bowel diaries has come into question given the unpredictable nature of incontinence in most patients, who are thought to be less likely to accurately record their accidents, particularly in public. A recently validated stool diary for measuring FI has been published as an abstract. ${ }^{31} \mathrm{~A}$ recent study compared the FISI scoring system with the more general Subject Global Assessment (SGA) system. ${ }^{64}$ As previously mentioned, FISI assesses all 4 types of leakage commonly found in the fecal incontinent population: gas, mucous, liquid stool and solid stool combined with frequency data. ${ }^{56}$ The SGA is a simple bedside assessment focusing on the overall severity of $\mathrm{FI}$ and is more predictive of improvement after intervention. ${ }^{64}$ FISI was better able to predict FI severity at baseline but less likely to detect responsiveness to treatment, while SGA was a better predictor for therapeutic responsiveness. ${ }^{64}$ An essential feature is that a complete evaluation of lower GI symptoms cannot be accomplished without an appropriate exam and adjunct diagnostic testing, wherever appropriate.

\section{Physical Exam With a Focus on the Digital Rectal Examination}

A quality physical exam is important in the comprehensive assessment of the patient with lower GI symptoms, and most importantly, it must include a complete digital rectal examination (DRE). Abdominal examination should be accompanied by assessment for succussion splash and palpation for stool in the colon that may suggest motility disorders. Bowel sounds should be auscultated. Musculoskeletal and neurologic exams can be useful to assess for possible contributing disease processes such as Ehlers-Danlos and Parkinson's disease, as constipation can be a presenting symptom in these conditions. ${ }^{65}$ In cases such as IBS, the physical exam may be entirely normal, but distention may be missed, and conversely in those with distention, an exaggerated lumbar lordosis could be a red herring.

In order to adequately assess for FI and dyssynergic defecation, a complete DRE must be performed. ${ }^{66}$ Despite its importance, it is performed rarely in clinical practice, even by practicing gastroenterologists. ${ }^{67}$ Another survey of 256, fourth year medical students revealed that $17 \%$ had never performed a DRE, and $48 \%$ were unsure of their findings. ${ }^{68}$ The reasons for not performing DRE are numerous, and generally boil down to a desire by clinicians to preserve patient's modesty or avoid the provider's unfamiliarity with the exam in general. It should be strongly emphasized that familiarity with a comprehensive DRE is essential for a clinician wishing to treat lower GI disorders. ${ }^{66}$

How to perform a good quality DRE has been systematically described recently ${ }^{66}$ and a video demonstration is also available. ${ }^{69}$ Setup for the exam requires a quality light source to visualize the entire perineum, gloves, gauze, lubrication, cotton-bud or Q-tip, and proctoscope if available. ${ }^{66,69}$ The exam itself and the rationale for its application should be explained to the patient prior, and a chaperone should generally be present for the protection of both 
Table 2. Evidence-based Summary of the Utility of the Diagnostic Tests in Patients With Suspected Colonic or Anorectal Motility Disorders (Modified From Sackett ${ }^{73}$ )

\begin{tabular}{|c|c|c|c|}
\hline Test & Clinical utility & Strength/Weakness & Comment \\
\hline $\begin{array}{l}\text { Blood tests (basic metabolic } \\
\text { panel, complete blood count, } \\
\text { thyroid function tests, etc) }\end{array}$ & $\begin{array}{l}\text { Rule out systemic or metabolic disorder } \\
\text { Easily obtainable in the clinic }\end{array}$ & $\begin{array}{l}\text { Low yield } \\
\text { Likely not cost-effective } \\
\text { strategy }\end{array}$ & $\begin{array}{l}\text { Not recommended for routine } \\
\text { evaluation particularly in } \\
\text { the absence of alarm features }\end{array}$ \\
\hline \multicolumn{4}{|l|}{ Imaging tests } \\
\hline Plain abdominal X-ray & $\begin{array}{l}\text { Identify excessive amount of stool in the } \\
\text { colon } \\
\text { Simple, inexpensive, widely available }\end{array}$ & $\begin{array}{l}\text { Lack of controlled studies } \\
\text { Purely qualitative data }\end{array}$ & $\begin{array}{l}\text { Recommended for routine } \\
\text { evaluation particularly in } \\
\text { the absence of alarm features }\end{array}$ \\
\hline Barium enema & $\begin{array}{l}\text { Identify megacolon, megarectum, stenosis, } \\
\text { diverticulosis, extrinsic compression and } \\
\text { intraluminal masses }\end{array}$ & $\begin{array}{l}\text { High radiation exposure } \\
\text { Difficult to tolerate for pa- } \\
\text { tients } \\
\text { Expensive }\end{array}$ & $\begin{array}{l}\text { Not recommended for routine } \\
\text { evaluation particularly in the } \\
\text { absence of alarm features }\end{array}$ \\
\hline Defecography & $\begin{array}{l}\text { Recognize dyssynergia, rectocele and } \\
\text { prolapse, excessive descent, megarectum, } \\
\text { Hirschsprung's disease }\end{array}$ & $\begin{array}{l}\text { High radiation exposure } \\
\text { Tolerability } \\
\text { Inconsistent methodology }\end{array}$ & $\begin{array}{l}\text { Used as an adjunct to anorectal } \\
\text { manometry }\end{array}$ \\
\hline Anorectal ultrasound & $\begin{array}{l}\text { Visualization of the internal anal sphincter } \\
\text { and puborectalis muscles }\end{array}$ & $\begin{array}{l}\text { Interobserver bias } \\
\text { Low availability }\end{array}$ & Primarily experimental \\
\hline MRI & $\begin{array}{l}\text { Simultaneous evaluation of global pelvic } \\
\text { floor anatomy and dynamic motion } \\
\text { Reveals pathology outside anorectum and } \\
\text { sphincter morphology }\end{array}$ & $\begin{array}{l}\text { Expensive } \\
\text { Lack of standardization } \\
\text { Likely not cost effective }\end{array}$ & $\begin{array}{l}\text { Used as an adjunct to anorectal } \\
\text { manometry }\end{array}$ \\
\hline \multicolumn{4}{|l|}{ Endoscopy } \\
\hline $\begin{array}{l}\text { Flexible sigmoidoscopy } \\
\text { and colonoscopy }\end{array}$ & $\begin{array}{l}\text { Direct visualization of the colon to exclude } \\
\text { mucosal lesions such as solitary rectal } \\
\text { ulcer syndrome, inflammation, or } \\
\text { malignancy }\end{array}$ & $\begin{array}{l}\text { Invasive } \\
\text { Risks of procedure } \\
\text { Typically not high yield in } \\
\text { cases of constipation and } \\
\text { anorectal pain }\end{array}$ & $\begin{array}{l}\text { Indicated in patients with warning } \\
\text { symptoms in patients under } 50 \\
\text { years } \\
\text { Indicated in all subjects older than } \\
50 \text { years for colorectal cancer } \\
\text { screening }\end{array}$ \\
\hline \multicolumn{4}{|l|}{ Physiologic testing } \\
\hline $\begin{array}{l}\text { Colonic transit study with } \\
\text { radiopaque markers }\end{array}$ & $\begin{array}{l}\text { Evaluate presence of slow, normal or rapid } \\
\text { colonic transit } \\
\text { Inexpensive and widely available }\end{array}$ & $\begin{array}{l}\text { Inconsistent methodology } \\
\text { Questionable validity } \\
\text { Radiation }\end{array}$ & $\begin{array}{l}\text { Useful to classify patients according } \\
\text { to the pathophysiological } \\
\text { subtypes }\end{array}$ \\
\hline $\begin{array}{l}\text { Colonic transit study with } \\
\text { scintigraphy }\end{array}$ & $\begin{array}{l}\text { Evaluate presence of slow, normal, or rapid } \\
\text { colonic transit } \\
\text { Provide evaluation of the whole gut transit }\end{array}$ & $\begin{array}{l}\text { Expensive } \\
\text { Time consuming } \\
\text { Low availability } \\
\text { Radiation }\end{array}$ & $\begin{array}{l}\text { Useful to classify patients according } \\
\text { to the pathophysiological } \\
\text { subtypes }\end{array}$ \\
\hline Wireless motility capsule & $\begin{array}{l}\text { Evaluate presence of slow, normal, or rapid } \\
\text { colonic transit } \\
\text { Provides evaluation of regional (gastric, } \\
\text { small bowel) and whole gut transit time }\end{array}$ & $\begin{array}{l}\text { Standardized method } \\
\text { Limited availability in } \\
\text { North America and } \\
\text { Europe } \\
\text { No radiation }\end{array}$ & $\begin{array}{l}\text { Useful to categorize patients into } \\
\text { slow transit and normal transit } \\
\text { Identifies upper GI dysmotility } \\
\text { Testing performed under } \\
\text { physiological conditions }\end{array}$ \\
\hline Anorectal manometry & $\begin{array}{l}\text { Identify dyssynergic defecation, rectal } \\
\text { hyposensitivity, rectal hypersensitivity, } \\
\text { impaired compliance, Hirschsprung's } \\
\text { disease }\end{array}$ & $\begin{array}{l}\text { Can be uncomfortable for } \\
\text { patients } \\
\text { Low availability } \\
\text { Questionable standardization }\end{array}$ & $\begin{array}{l}\text { Useful to establish the diagnoses } \\
\text { of Hirschsprung's disease and } \\
\text { dyssynergic defecation } \\
\text { Identify rectal hyposensitivity and } \\
\text { rectal hypersensitivity in IBS }\end{array}$ \\
\hline
\end{tabular}


Table 2. Continued

\begin{tabular}{|c|c|c|c|}
\hline Test & Clinical utility & Strength/Weakness & Comment \\
\hline Balloon expulsion test & $\begin{array}{l}\text { Simple, non expensive, bedside assessment } \\
\text { of the ability to expel a simulated stool } \\
\text { Identify dyssynergic defecation }\end{array}$ & Lack of standardization & $\begin{array}{l}\text { Normal balloon expulsion test does } \\
\text { not exclude dyssynergia } \\
\text { Should be interpreted alongside the } \\
\text { results of the other anorectal tests }\end{array}$ \\
\hline Colonic manometry & $\begin{array}{l}\text { Identify colonic myopathy, neuropathy or } \\
\text { normal function facilitating selection of } \\
\text { patients for surgery }\end{array}$ & $\begin{array}{l}\text { Invasive, not widely avail- } \\
\text { able, lack of standardiza- } \\
\text { tion }\end{array}$ & Adjunct to colorectal function tests \\
\hline $\begin{array}{l}\text { Translumbosacral anorectal } \\
\text { magnetic stimulation }\end{array}$ & $\begin{array}{l}\text { Measures conduction velocity of spinal } \\
\text { nerves responsible for defecation }\end{array}$ & $\begin{array}{l}\text { Standardized } \\
\text { Not widely available }\end{array}$ & $\begin{array}{l}\text { Able to identify lumbar plexus and } \\
\text { sacral plexus neuropathy } \\
\text { contributing to lower GI } \\
\text { symptoms, particularly fecal } \\
\text { incontinence and anorectal } \\
\text { pain disorders } \\
\text { Identify neuropathy at rectum and } \\
\text { anal region }\end{array}$ \\
\hline
\end{tabular}

GI, gastrointestinal; IBS, irritable bowel syndrome.

the provider and patient. The patient should be placed in the left lateral position with their knees flexed at the hip. A visual inspection is the first step, with careful assessment for hemorrhoids, fissures, trauma, scars, or other obvious defects. The anocutaneous reflex should be next assessed by gently stroking the perianal skin towards the anus in a 4-quadrant pattern. The anus should contract, and impairment or absence of this reflex suggests neuronal injury. ${ }^{25}$ After lubrication, a gloved index finger should be inserted into the rectum. Masses, strictures, tenderness or spasm should be appreciated during this step, and presence or absence of stool should be noted at this time, as presence of stool that the patient is unaware is highly suggestive of rectal hyposensitivity. ${ }^{66}$ The patient should then be asked to squeeze, as if trying to hold back stool and the resting/ active tone of the anal sphincter should be qualitatively assessed. It is generally recommended to repeat any maneuvers to confirm any findings. Next, the patient should be instructed to bear down, as if attempting to defecate. The provider's left hand should be on the patient's abdomen during this step, in order to assess both abdominal push effort, and anal relaxation simultaneously. A normal maneuver will consist of abdominal muscle contraction, relaxation of the anal sphincter, and perineal descent. ${ }^{66}$ Abnormal findings during the DRE such as weak anal sphincters, paradoxical anal contraction or poor relaxation suggest that further anorectal testing is indicated to elucidate underling mechanisms causing the patient's symptoms. ${ }^{66,67,70}$ The sensitivity and specificity of DRE in identifying dyssynergia is very high, ${ }^{71}$ although there is evidence that experience of the provider performing the exam also plays a role. ${ }^{72}$

\section{Diagnostic Tests for Lower Gastrointestinal Symptoms}

After the assessment and physical exam, appropriate diagnostic assessment should follow (Table 2). ${ }^{73}$ Laboratory testing, including complete blood cell count, serum glucose, creatinine, calcium, and thyroid-stimulating hormone may be performed judiciously, to exclude an underlying metabolic disorder causing bowel symptoms. ${ }^{3,8,9}$ Endoscopic evaluation is usually not helpful, but should be considered in a patient presenting with a new change in bowel symptoms $>50$ years of age or with alarm signs (weight loss, anemia, nocturnal symptoms, and bleeding). ${ }^{2,3,7}$ Radiologic studies have long held a role in assessing lower GI symptoms. Plain Xray of the abdomen can be helpful to detect stool retention in the colon, $^{74}$ and assess for megacolon and aganglionic bowel that may suggest Hirschsprung's disease.

\section{Motility Studies}

For specifically evaluating colonic motor function, there are several methods of assessing colonic transit as well as colonic manometry. ${ }^{75,76}$ Colonic transit studies may be helpful in distinguishing slow transit constipation from IBS-C and dyssynergic defecation, although $65 \%$ of patients with dyssynergic defecation may have secondary slow transit. ${ }^{18,60}$ Traditionally, radiopaque (Sitzmarkers) markers studies have been used for this purpose. A patient will 
ingest these markers (typically 1 capsule with 24 markers), with subsequent X-ray of the colon on day 5 at 120 hours. ${ }^{75,76}$ Retention of $>5$ markers is high suggestive of slow transit constipation. ${ }^{75,76}$ The pattern of retention is not very helpful, as markers throughout the colon or those confined to the recto-sigmoid colon do not distinguish between slow transit and dyssynergic defecation. ${ }^{75,76}$

A more modern, superior option is the utilization of wireless motility and $\mathrm{pH}$ monitoring system (Smartpill). ${ }^{77}$ This capsule has sensors that continuously monitor pressure, $\mathrm{pH}$, and temperature from its surroundings, which are transmitted to an external receiver worn by a patient. It has the advantages of assessing regional and whole gut transit times. wireless motility capsules have been validated against the radiopaque markers in patients with chronic constipation. ${ }^{77}$ Normative values for this study are 2-5 hours (gastric), 2-6 hours (small bowel), 10-59 hours (colon), and 14-70 hours (whole gut transit time).$^{78}$ The protocol for the usage of the motility capsule is fairly straight forward. ${ }^{77,78}$ Patients begin with an overnight fast and discontinuation of medications that may alter gastric $\mathrm{pH}$ or motility. The patient is given a standardized meal consisting of a $260-\mathrm{kcal}$ nutrient bar. The patient swallows the wireless motility capsules and then refrains from further eating for at least 6 hours. The patient wears a recorder device that detects capsule data for the next 24-120 hours and returns it at the end of the study. The capsule has the main advantage of providing information about gastric, small bowel, and colonic transit as well as motility, and avoid radiation exposure that is inherent in nuclear medicine gastric emptying studies and colonic transit studies. ${ }^{76-78}$

A limitation of transit or wireless capsule studies is that while they can establish the diagnosis of slow transit, they cannot provide pathophysiological explanation for colonic motor on nerve function. $^{75}$ On the other hand, colonic manometry can give detailed information about the pattern of motor activity in the colon, and if combined with a barostat balloon study can provide useful complementary information regarding colonic sensation, tone, and compliance. ${ }^{76,79,80}$ Typical indications for colonic manometry include slow transit constipation that is refractory to therapy and suspicion for colonic pseudo-obstruction. Three cardinal phasic responses are assessed: high amplitude propagating contractions, gastrocolonic response after meal, and waking-up response. ${ }^{76,79,80}$ These can be used to distinguish between colonic neuropathy and myopathy which have different management strategies. ${ }^{79,80}$ Ideally, colonic manometry should be performed to investigate the underlying pathology of slow transit constipation before considering colectomy, but often this is not performed in clinical practice. ${ }^{80}$ Magnetic resonance and dynamic defecography utilizing barium contrast are also useful tools in evaluating perineal anatomy, particularly in situations when surgical intervention is being considered. ${ }^{81}$

For constipation, evaluation of outlet obstruction or dyssynergic defecation is just as essential as evaluating for slow transit. ${ }^{76,82}$ Anorectal manometry (ARM) has long been a hallmark of the constipation workup. ${ }^{82}$ Its ability to assess anorectal pressure relationships, in addition to rectal compliance and sensitivity, is enormously useful in characterizing anorectal dysfunction. ${ }^{4,760,76,82}$ Since the treatment for a significant number of anorectal diseases involves biofeedback, ARM is very useful in guiding the biofeedback regimen in addition to assessing responses to treatment. ${ }^{83}$ The more recently implemented high definition 3-dimensional manometry (HDM) uses 256 circumferential transducers to define the anal pressures with higher accuracy, but currently there is no evidence that HDM is superior to conventional manometry. ${ }^{81} \mathrm{ARM}$ is typically combined with the balloon expulsion test. ${ }^{3,7,84}$ A $50-60 \mathrm{~mL}$ water filled balloon is inflated in the patient's rectum, after which the patient is instructed to expel the balloon. A defecation time greater than 60 seconds indicates an abnormal test. ${ }^{60,80}$ Its overall simplicity is its greatest advantage, as it can be done in an office setting and it is highly sensitive for detecting dyssynergic defecation. ${ }^{8,62}$

Spinal neuropathy has been shown to play a significant role in the development of $\mathrm{FI}^{3,28}$ and therefore the identification and possible treatment of this condition is essential..$^{85}$ Translumbrosacral anorectal magnetic stimulation is a novel, comprehensive, nerve conduction test that can help to characterize lumbosacral neuropathy contributing to FI symptoms. ${ }^{85-87}$ Magnetic stimulation induced motor evoked potentials provide information on the integrity of spinoanorectal pathways that govern continence and defecations and have been shown to be abnormal in patients with FI (Fig. 4). ${ }^{85-87}$ While this test is not widely available, identifying the neuronal latencies in the lumbosacral pathways, and detecting anal or rectal neuropathy could open up new avenues of therapy. ${ }^{88}$ Anal ultrasound test quantifies the thickness of the puborectalis, external anal sphincter, and the internal anal sphincter muscles, and can reveal defects in these structures from previous puborectalis usually childbirth or surgery, and is cheaper than MRI.,84

A new treatment, translumbosacral neuromodulation therapy, which involves the administration of repetitive pulses of magnetic energy to stimulate the lumbar and sacral plexus neuronal pathways, in order to promote nerve regeneration, using the principle of neuroplasticity has been reported. ${ }^{88}$ In this study, 33 patients showed significant improvements in the number of weekly FI episodes, SGA scores, and Facial Injury Severity Scale scores, and revealed that a lower frequency of magnetic stimulation at $1 \mathrm{~Hz}$ was most 
Trans-lumbar

rectal motor evoked potential

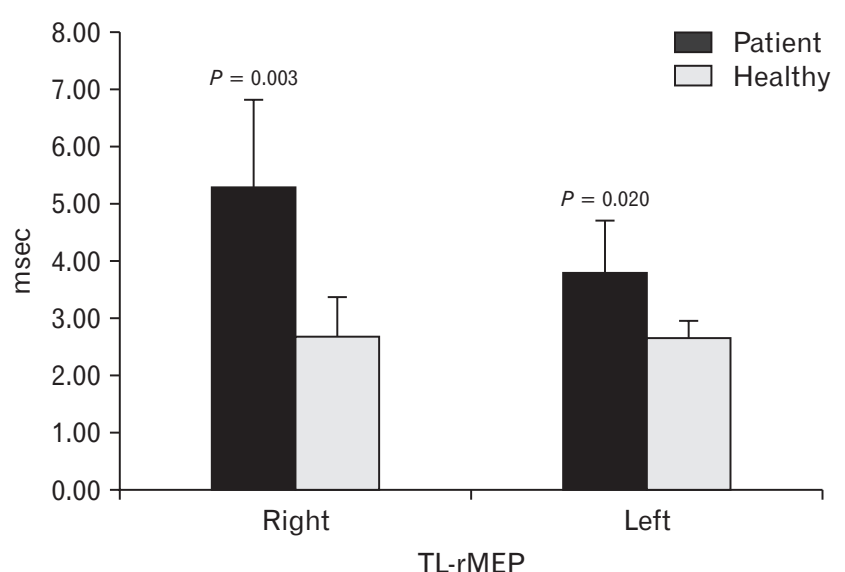

Trans-lumbar

anal motor evoked potential

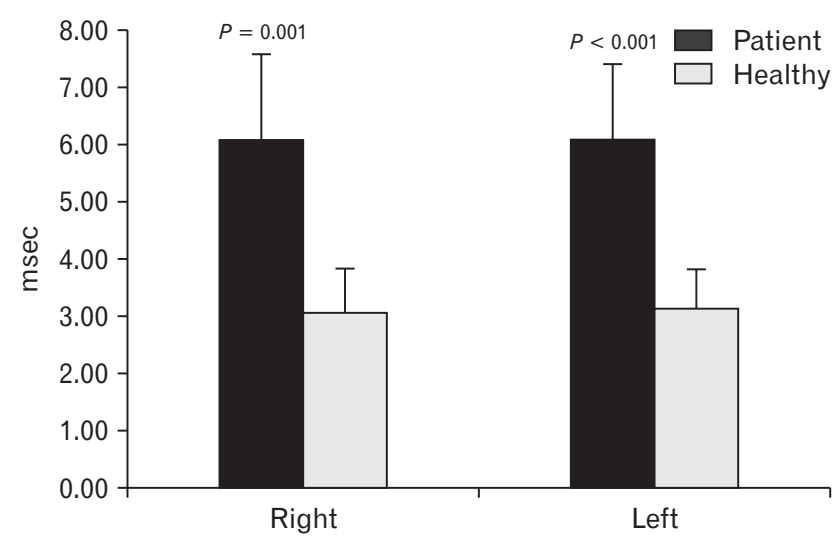

TL-aMEP

Figure 4. This shows the mean latency $( \pm \mathrm{SD})$ for the bilateral translumbar motor evoked potentials from the rectum and anal canal in patients with fecal incontinence and healthy controls. Adapted from Rao et al. ${ }^{86}$

Table 3. Future Avenues for Research and Gaps in Knowledge in the Assessment of Colonic and Anorectal Disorders

- Cost effective and clinically pragmatic method for identifying IBS in clinic using new questionnaire(s) and/or biomarkers

- Generate normative data using the IAPWG consensus protocol for anorectal manometry

- Assess the clinical significance and algorithmic flow of the London Protocol for anorectal disorders

- Cost effectiveness and comparative utility of wireless motility capsule with radio-opaque markers in the assessment of colonic transit in chronic constipation

- Comparative evaluation of IBS severity tools and development of a simpler user-friendly tool for adoption by clinicians in practice

- Comparative evaluation of the fecal incontinence severity assessment tools, and to identify a practical and simple tool for clinical assessment of FI severity

- Assessment of and adherence to the AGA guidelines and/or Rome diagnostic criteria for constipation and IBS by practitioners in the community

IBS, irritable bowel syndrome; IAPWG, International Anorectal Physiology Working Group; FI, fecal incontinence; AGA, American Gastroenterological Association.

beneficial. $^{88}$ More investigation is needed in this area, including higher power randomized controlled trials. It is also unclear whether this therapy would have an effect on patients with significant spinal cord injury or anal sphincter defects. Finally, despite these advances in clinical diagnosis and management, there are several gaps in our knowledge that we have identified and for which we propose several avenues of investigation. These could be useful in the future for improving the diagnosis and treatment of patients with suspected colonic or anorectal disorders (Table 3 ).

\section{Conclusion}

The assessment of lower GI symptoms suggestive of either colonic or anorectal motility disorder(s) remains a challenge for most clinicians. In addition to a detailed inquiry of symptoms that support a diagnosis of chronic constipation, dyssynergic defecation, IBS, FI, and other anorectal disorders, currently there are several objective scoring systems that can facilitate a standardized assessment. The BSFS and a prospective stool and symptom diary, ideally with a phone App, are excellent tools for understanding and translating patient complaints into definable, diagnostic categories. Physical exam, especially a high quality DRE is essential for characterizing these disorders. These findings should be complemented wherever appropriate with physiologic and imaging tests before reaching a final diagnosis. ${ }^{73}$

Financial support: This work was supported from the National Institute of Health (Grants No. R01 DK121003-01 and UO1 DK115575-01).

\section{Conflicts of interest: None.}


Author contributions: Bryan Curtin, Enoe Jimenez, and Satish S C Rao contributed equally in the ideas, research data, figures, and tables.

\section{References}

1. Perry AF, Dellon ES, Lund J, et al. Burden of gastrointestinal disease in the United States: 2012 update. Gastroenterology 2012;143:1179-1187, e3.

2. Lacy BE, Mearin F, Chang L, et al. Bowel disorders. Gastroenterology 2016;150:1393-1407.

3. Rao SS, Bharucha AE, Chiarioni G, et al. Anorectal disorders. Gastroenterology 2016;150:1430-1442, e4.

4. Rao SSC, Welcher KD, Leistikow JS. Obstructive defecation: a failure of rectoanal coordination. Am J Gastroenterol 1998;93:1042-1050.

5. Singh $G$, Lingala $V$, Wang $H$, et al. Use of health care resources and cost of care for adults with constipation. Clin Gastroenterol Hepatol 2007;5:1053-1058.

6. Sethi S, Mikami S, Leclair J, et al. Inpatient burden of constipation in the United States: an analysis of national trends in the United States from 1997 to 2010. Am J Gastroenterol 2014;109:250-256.

7. Rao SSC, Rattanakovit K, Patcharatrakul T. Diagnosis and management of chronic constipation in adults. Nat Rev Gastroenterol Hepatol 2016;13:295-305.

8. Bharucha AE, Pemberton JH, Locke GR 3rd. American Gastroenterological Association techinical review on constipation. Gastroenterology 2013;144:218-238.

9. ASGE Standards of Practice Committee. The role of endoscopy in the management of constipation. Gastrointest Endosc 2014;80:563-565.

10. Herz MJ, Kahan E, Zalevski S, Aframian R, Kuznitz D, Reichman S. Constipation: a different entity for patients and doctors. Fam Pract 1996;13:156-159.

11. Sandler RS, Drossman DA. Bowel habits in young adults not seeking health care. Dig Dis Sci 1987;32:841-845.

12. Rajindrajith S, Devanarayana NM, Lakmini C, Subasinghe V, de Silva $\mathrm{DH}$, Benninga MA. Association between child maltreatment and constipation: a school-based survey using Rome III criteria. J Pediatr Gastroenterol Nutr 2014;58:486-490.

13. Rao SS, Tuteja AK, Vellema T, Kempf J, Stessman M. Dyssynergic defecation: demographics symptoms, stool patters and quality of life. J Clin Gastroenterol 2004;38:680-685.

14. Suares NC, Ford AC. Prevalence of, and risk factors for, chronic idiopathic constipation in the community: systematic review and metaanalysis. Am J Gastroenterol 2011;106:1582-1591.

15. Yan Y, Jimenez E, Sharma A, et al. How useful is constipation stool App compared to paper stool diary - randomized study of constipation and healthy subjects. Gastroenterology 2020;158:S-400.

16. Chiarioni G, Kim SM, Whitehead WE. Sa2038 dyssynergic defecation can be diagnosed by questionnaire and physical examination. Gastroenterology 2013;144:S-366.

17. Bharucha AE, Locke GR, Zinsmeister AR, et al. Differences between painless and painful constipation among community women. Am J Gastroenterol 2006;101:604-612.

18. Everhart JE, Renault PF. Irritable bowel syndrome in office-based practice in the United States. Gastroenterology 1991;100:998-1005.

19. Quigley EM, Fried M, Gwee KA, et al. World Gastroenterology Organization global guidelines irritable bowel syndrome: a global perspective update September 2015. J Clin Gastroenterol 2016;50:704-713.

20. Mudipalli RS, Remes-Troche JM, Andersen L, Rao SS. Functional chest pain: esophageal or overlapping functional disorder. J Clin Gastroenterol 2007;41:264-269.

21. Azpiroz F, Bouin M, Camilleri M, et al. Mechanisms of hypersensitivity in IBS and functional disorders. Neurogastroenterol Motil 2007;19:6288.

22. Lee YY, Annamalai C, Rao SSC. Post-infectious irritable bowel syndrome. Curr Gastroenterol Rep 2017;19:56.

23. Spiegel BM, Bolus R, Agarwal N, et al. Measuring symptoms in the irritable bowel syndrome: development of a framework for clinical trials. Aliment Pharmacol Ther 2010;32:1275-1291.

24. Drossman DA. History of functional gastrointestinal symptoms and disorders and chronicle of the Rome Foundation. In: Drossman DA, eds. Rome IV functional gastrointestinal disorders: disorders of gut-brain interaction. Raleigh: Rome Foundation, Inc. 2016:549-576.

25. Rao SS. Diagnosis and management of fecal incontinence. Am J Gastroenterol 2004;99:1585-1604.

26. Bharucha AE, Dunivan G, Goode PS, et al. Epidemiology, pathophysiology, and classification of fecal incontinence: state-of-the-science summary for the National Institute of Diabetes and Digestive and Kidney Disease (NIDDK) workshop. Am J Gastroenterol 2015;110:127-136.

27. Whitehead WE, Borrud L, Goode PS, et al. Fecal incontinence in US adults: epidemiology and risk factors. Gastroenterology 2009;137:512517, e1-e2.

28. Rao SS. Pathophysiology of adult fecal incontinence. Gastroenterology 2004;126(1 suppl 1):S14-S22.

29. Engel AF, Kamm MA, Bartram CI, Nicholls RJ. Relationship of symptoms in faecal incontinence to specific sphincter abnormalities. Int $\mathrm{J}$ Colorectal Dis 1995;10:152-155.

30. Madoff RD, Williams JG, Caushaj PF. Fecal incontinence. N Engl J Med 1992;326:1002-1007.

31. Jimenez E, Yan Y, Sharma A, et al. Fecal incontinence (FI) stool App is a reliable and valid instrument for leakage assessment: RCT in FI and healthy subjects. Gastroenterol 2020;158:S-380.

32. Rao SS, Sanku A, Yan Y, et al. Electronic App vs paper form stool diary for fecal incontinence. J Gastroenterol Hepatol 2019;34:457-457.

33. Yan Y, Xiang X, Sharma A, et al. Validation of a perspective stool diary instrument for assessment of fecal incontinence. Gastroenterology 2019;156:S-355.

34. Rao SS. Current and emerging treatment options for fecal incontinence. J Clin Gastroenterol 2014;48:752-764.

35. Grimaud JC, Bouvier M, Naudy B, Guien J, Salducci J. Manometric and radiologic investigations and biofeedback treatment of chronic idiopathic anal pain. Dis Colon Rectum 1991;34:690-695.

36. Chiarioni G, Nardo A, Vantini I, Romito A, Whitehead WE. Biofeed- 
back is superior to electrogalvanic stimulation and massage for treatment of levator ani syndrome. Gastroenterology 2010;4:1321-1329.

37. Erdogan A, Coss-Adame E, Dewitt A, Rao S. Pathophysiology of levator ani syndrome: evaluation of spino-anorectal (enteric) neuromuscular function. OP002. Neurogastroenterol Motil 2014;26:1-2.

38. Yan Y, Erdogan A, Xiang X, Dewitt A, Sharma A, Rao SS. Pathoetiology of levator ani syndrome: evaluation of spinoanorectal neuropathy and anorectal sensori-motor. Gastroenterology 2020;158:S-2.

39. de Parades V, Etienney I, Bauer P, Taouk M, Atienza P. Proctalgia fugax: demographic and clinical characteristics. What every doctor should know from a prospective study of 54 patients. Dis Colon Rectum 2007;50:893898.

40. Thompson WG. Proctalgia fugax in patients with irritable bowel, peptic ulcer, or inflammatory bowel disease. Am J Gastroenterol 1984;79:450452 .

41. Thompson WG. The irritable bowel. Gut 1984;25:305-320.

42. Prichard DO, Bharucha AE. Recent advances in understanding and managing chronic constipation. F1000Res 2018;7:F1000 Faculty Rev1640.

43. Ashraf W, Park F, Lof J, Quigley EM. An examination of the reliability of reported stool frequency in the diagnosis of idiopathic constipation. Am J Gastroenterol 1996;91:26-32.

44. Meduri K, Brown C, Attaluri A, Valestin J, Rao S. Validation of a prospective stool diary for assessment of constipation. ANMS 2011. Neurogastroenterol Motil 2011;23(suppl 1):21

45. Agachan F, Chen T, Pfeifer J, Reissman P, Wexner SD. A constipation scoring system to simplify evaluation and management of constipated patients. Dis Colon Rectum 1996;39:681-685.

46. Sharma A. Rao SS. Epidemiological trends and diagnostic evaluation of fecal incontinence. Gastroenterol Hepatol 2020;16:302-309.

47. Heaton KW, Radvan J, Cripps H, Mountford RA, Braddon FE, Hughes AO. Defecation frequency and timing, and stool form in the general population: a prospective study. Gut 1992;33:818-824.

48. Frazzitta G, Ferrazzoli D, Folini A, Palamara G, Maestri R. Severe constipation in parkinson's disease and in parkinsonisms: prevalence and affecting factors. Front Neurol 2019;10:621.

49. Frank L, Kleinman L, Farup C, Taylar L, Miner P Jr. Psychometric validation of a constipation symptom assessment questionnaire. Scand $\mathrm{J}$ Gastroenterol 1999;34:870-877.

50. Rao SS. Plecanatide: a new guanylate cyclase agonist for the treatment of chronic idiopathic constipation. Therap Adv Gastroenterol 2018;11:1756284818777945.

51. Marquis P, De La Loge C, Dubois D, McDermott A, Chassany O. Development and validation of the patient assessment of constipation quality of life questionnaire. Scand J Gastroenterol 2005;40:540-551.

52. Wilson IB, Cleary PD. Linking clinical variables with healthrelated quality of life: a conceptual model of patient outcomes. JAMA 1995;273:59-65

53. Almario CV, Spiegel BM. Employing irritable bowel syndrome patientreported outcomes in the clinical trenches. Clin Gastroenterol Hepatol 2018;16:462-466.e2.

54. Jorge JM, Wexner SD. Etiology and management of fecal incontinence.
Dis Colon Rectum 1993;36:77-97.

55. Vaizey CJ, Carapeti E, Cahill JA, Kamm MA. Prospective comparison of faecal incontinence grading systems. Gut 1999;44:77-80.

56. Rockwood TH, Church JM, Fleshman JW, et al. Patient and surgeon ranking of the severity of symptoms associated with fecal incontinence: the fecal incontinence severity index. Dis Colon Rectum 1999;42:15251532.

57. Rockwood TH, Church JM, Fleshman JW, et al. Fecal incontinence quality of life scale: quality of life instrument for patients with fecal incontinence. Dis Colon Rectum 2000;43:9-16; discussion 16-17.

58. Noelting J, Zinsmeister AR, Bharucha AE. Validating endpoints for therapeutic trials in fecal incontinence. Neurogastroenterol Motil 2016;28:1148-1156.

59. Rao SS. Endpoints for therapeutic interventions in fecal incontinence: small step or game changer. Neurogastroenterol Motil 2016;28:11231133.

60. Rao SSC, Mudipalli RS, Stessman M, Zimmerman B. Investigation of the utility of colorectal function test and Rome II criteria in dyssynergic defecation (Anismus). Neurogastroenterol Motil 2004;16:589-596.

61. Ratuapli SK, Bharucha AE, Noelting J, Harvey DM, Zinsmeister AR. Phenotypic identification and classification of functional defecatory disorders using high-resolution anorectal manometry. Gastroenterology 2013;144:314-322, e2.

62. Minguez M, Herreros B, Sanchiz V, et al. Predictive value of the balloon expulsion test for excluding the diagnosis of pelvic floor dyssynergia in constipation. Gastroenterology 2004;126:57-62.

63. Hill J, Corson RJ, Brandon H, Redford J, Faragher EB, Kiff ES. History and examination in the assessment of patients with idiopathic fecal incontinence. Dis Colon Rectum 1994;37:473-477.

64. Wan Q, Yan Y, Xing X, et al. Towards an optimal tool for assessment of fecal incontinence (FI) severity and therapeutic responsiveness. Gastroenterology 2019;156:S-354.

65. Zweig A, Schindler V, Becker AS, van Maren A, Pohl D. Higher prevalence of joint hypermobility in constipation predominant irritable bowel syndrome. Neurogastroenterol Motil 2018;30:e13353.

66. Rao SS. Rectal exam: yes, it can and should be done in a busy practice! Am J Gastroenterol 2018;113:635-638.

67. Wong RK, Drossman DA, Bharucha AE, et al. The digital rectal examination: a multicenter survey of physicians' and students' perceptions and practice patterns. Am J Gastroenterol 2012;107:1157-1163.

68. Lawrentschuk N, Bolton DM. Experience and attitudes of final-year medical students to digital rectal examination. Med J Aust 2004;181:323325.

69. Rao SS. Digital rectal examination: video demonstration: Neurogut, Inc. 2018. ISBN:9780578635569.

70. Soh JS, Lee HJ, Jung KW, et al. The diagnostic value of a digital rectal examination compared with high-resolution anorectal manometry in patients with chronic constipation and fecal incontinence. Am J Gastroenterol 2015;110:1197-1204.

71. Tantiphlachiva K, Rao P, Attaluri A, Rao SS. Digital rectal examination is a useful tool for identifying patients with dyssynergia. Clin Gastroenterol Hepatol 2010;8:955-960. 
72. Yan Y, Tantiphlachiva K, Bhagatwala J, et al. Does coaching improve a trainees' ability to perform a more accurate dre? a prospective study. Gastroenterology 2019;156:S-354.

73. Sackett DL. Rules of evidence and clinical recommendations on use of antithrombotic agents. Chest 1986;89(2 suppl):2S-3S.

74. Park SY, Khermani D, Nelson AD, Eckert D, Camilleri M. Rectal gas volume measured by computerized tomography identifies evacuation disorders in patients with constipation. Clin Gastroenterol Hepatol 2017; 15:543-552, e4.

75. Camilleri M. Bharucha AE, di Lorenzo C, et al. American Neurogastroenterology and Motility Society consensus statement on intraluminal measurement of gastrointestinal and colonic motility in clinical practice. Neurogastroenterol Motil 2008;20:1269-1282.

76. Rao SS, Camilleri M. Clinical approach to constipation. In: Podolsky D, eds. Yamada's textbook of gastroenterology. West Sussex: Wiley Blackwell 2016;757-780.

77. Rao SS, Kuo B, McCallum RW, et al. Investigation of colonic and whole-gut transit with Wireless motility capsule and radiopaque markers in constipation. Clin Gastroenterol Hepatol 2009;7:537-544.

78. Lee YY, Erdogan A, Rao SS. How to assess regional and whole gut transit time with wireless motility capsule. J Neurogastroenterol Motil 2014;20:265-270.

79. Lee YY, Erdogan A, Rao SS. How to perform and assess colonic manometry and barostat study in chronic constipation. J Neurogastroenterol Motil 2014;20:547-552.

80. Rao SS, Singh S. Clinical utility of colonic and anorectal manometry in chronic constipation. J Clin Gastroenterol 2010;44:597-609.
81. Basilisco G, Bharucha AE. High-resolution anorectal manometry: an expensive hobby or worth every penny? Neurogastroenterol Motil 2017;29:e13125.

82. Diamant NE, Kamm MA, Wald A, Whitehead WE. AGA technical review on anorectal testing techniques. Gastroenterology 1999;116:735760.

83. Rao SS, Benninga MA, Bharucha AE, Chiarioni G, Di Lorenzo C, Whitehead WE. ANMS-ESMN-position paper and consensus guidelines on biofeedback therapy for anorectal disorders. Neurogastroenterol Motil 2015;27:594-609.

84. Wald A, Bharucha AE, Cosman BC, Whitehead WE. ACG clinical guideline: management of benign anorectal disorders. Am J Gastroenterol 2014;109:1141-1157.

85. Tantiphlachiva K, Attaluri A, Valestin J, Yamada T, Rao SS. Translumbar and transsacral motor-evoked potentials: a novel test for spino-anorectal neuropathy in spinal cord injury. Am J Gastroenterol 2011;106:907-914.

86. Rao SS, Coss-Adame E, Tantiphlachiva K, Attaluri A, Remes-Troche J. Translumbar and transsacral magnetic neurostimulation for the assessment of neuropathy in fecal incontinence. Dis Colon Rectum 2014;57:645-652.

87. Yan Y, Herekar A, Gu G, et al. Clinical utility of translumbosacral anorectal magnetic stimulation (TAMS) test in anorectal disorders. Gastroenterology 2019; 156:S354-S355.

88. Rao SS, Xiang X, Sharma A, et al. Translumbosacral neuromodulation therapy for fecal incontinence: a randomized frequency response trial. Am J Gastroenterol Published Online First: 29 Jul 2020. doi: 10.14309/ ajg.0000000000000766. 